Article

\title{
Changes in the Innovation- and Marketing-Habits of Family SMEs in the Foodstuffs Industry, Caused by the Coronavirus Pandemic in Hungary
}

\author{
Norbert Bajkó ${ }^{1}$, Zsolt Fülöp ${ }^{1}$ and Kinga Nagyné Pércsi ${ }^{2, * *(1)}$ \\ 1 Doctoral School of Economic and Regional Sciences, Hungarian University of Agriculture and Life Sciences, \\ 2100 Gödöllő, Hungary; norbert.bajko@gmail.com (N.B.); zsoltf8905@gmail.com (Z.F.) \\ 2 Institute of Agricultural and Food Economics, Hungarian University of Agriculture and Life Sciences, \\ 2100 Gödöllő, Hungary \\ * Correspondence: nagyne.percsi.kinga@uni-mate.hu
}

Citation: Bajkó, N.; Fülöp, Z.; Pércsi, K.N. Changes in the Innovation- and Marketing-Habits of Family SMEs in the Foodstuffs Industry, Caused by the Coronavirus Pandemic in Hungary. Sustainability 2022, 14, 2914. https://doi.org/10.3390/su14052914 Academic Editors: Fogarassy Csaba, Gyuricza Csaba and Marc A. Rosen

Received: 16 November 2021

Accepted: 23 February 2022

Published: 2 March 2022

Publisher's Note: MDPI stays neutral with regard to jurisdictional claims in published maps and institutional affiliations.

Copyright: (c) 2022 by the authors. Licensee MDPI, Basel, Switzerland. This article is an open access article distributed under the terms and conditions of the Creative Commons Attribution (CC BY) license (https:// creativecommons.org/licenses/by/ $4.0 /)$.

\begin{abstract}
The economic specialties caused by the global coronavirus pandemic completely changed everyday life regarding certain sectors. For the small and medium enterprises, processing during the pandemic held several significant challenges, such as: cost-efficient operations, hardship of keeping employees, efficient management of innovation and various corporate activities, keeping the customers, etc. Many enterprises saw severe damages indirectly from the coronavirus pandemic, as society itself had its habits significantly changed, thereby necessitating changes in strategy for small and medium enterprises, most notably for local service providers and producers that have no delivery service. In order to solve the issue at hand, several governments tried applying a variety of solutions - mostly by financing the enterprises in question. The goal of the authors is to understand the current operation of innovation initiatives that small and medium enterprises have post-COVID19 , and to obtain a clear view on changes in marketing habits. Furthermore, the analysis concentrates on the following: the state of family SMEs dealing in foodstuffs, and how to create a future view for such members of the sector by identifying best practices. Using data collected during 2020 and 2021, and employing descriptive statistics and a conjoint analysis, the authors wished to see how the coronavirus pandemic affected SMEs, detect the changes in their marketing and innovation policy due to the pandemic, and help them create core business strategy via consumer feedback. Authors found that SMEs had to innovate by 2021 beyond their 2019 expectations, and that customers had partially validated their endeavors through their answers.
\end{abstract}

Keywords: SME; foodstuffs; family enterprise; sustainability; SME innovation; marketing strategy; coronavirus

\section{Introduction}

The effects of the coronavirus pandemic were unexpected across the globe, and caused both the economy and society to undergo significant changes in response to its pressure on our everyday lives. The most notable effect of the coronavirus on society and national economies worldwide is uncertainty - the situation was unexpected for the global community, and handling it caused issues for a wide variety of actors across society. Caggiano et al. showed that the uncertainty of the coronavirus pandemic not only caused global shock, it had direct effects on, for example, industrial production, reducing it by $14 \%$ worldwide [1]. Similarly, Baker et al. reviewed the coronavirus pandemic's effects on the financial world, and concluded that not only were the effects of the coronavirus pandemic on financial markets intense, the volatility of financial markets went as far as to overtake the recent global economic depression's volatility in terms of extremity [2]. Beside uncertainty, a wide array of other problems also arose-due to the quarantine period, many laborers lost their work, and several industries, most notably tourism and catering, suffered a severe hit in 
business. Further areas that suffered specific impacts from the coronavirus pandemic are almost too many to count; they have faced new challenges due to the unexpected change in situation. Political communication and politics had to engineer a fine balance between intervention and political security [3]. Healthcare and related industries had to deal with significant pressure due to the changes in people's everyday lives [4]. Transport had to sustain the mobility of the population in increasingly high-pressure circumstances [5]. Public services such as electric energy supply had to deal with unexpected loads due to the quarantine measures [6], and due to the post-treatment economic incentives, emission management and clean technology development will have significant increases in pressure [7]. Considering the impacts of COVID-19 on the aforementioned and more, and looking at the employment structure in Hungary, it is reasonable to say that the sector most impacted by the coronavirus pandemic is the sector of small and medium enterprises. Hungary is similar to other European Union countries in the sense that the SME sector is the one employing the vast majority of those in employment in the private sector. However, mostly due to size constraints, SMEs are more severely affected by impacts on business that have less of an effect on large enterprises. Albeit the coronavirus pandemic also opened opportunities when it comes to rationalizing SME management, it is overall not contested that the negatives on the economy outweigh the positives. For example, Tavares et al. argue that the coronavirus pandemic and its impact brought forth the necessity of teleworking, and recommend companies to rethink their approach to it [8]. Contrary to the argument of Tavares et al., Azevedo et al. state that digitization as a barrier is a heavy issue for SMEs in Europe. Competitiveness itself is compromised without them, yet many decision-makers simply discard opportunities related to it, mainly due to the necessary skill and competency ceiling, and most notably entry costs [9]. In a context highly disadvantageous to the SME sector, the coronavirus pandemic can be a lethal issue, which is why it is necessary to search for opportunities for improvement as much as possible. Furthermore, since the SME sector has more budget constraints than the large enterprise sector, it is advantageous to find solutions for upcoming issues that are as cost-efficient as possible.

Instead of launching large investment projects to preserve or improve competitiveness, it is therefore better to rationalize and extend already existing protocols and methods to cut costs, and, at the same time, increase income. However, is it possible to do so unless the business conforms to the changes in environment?

Most SMEs were not capable of cutting costs and increasing income at the same time. A prime example is the group of family SMEs, which had even more severe constraints than most other SMEs. These firms are highly vulnerable to the effects of the coronavirus pandemic, and are, in general, lacking in the knowhow and capability for alleviating them [10]. For family SMEs, it is imperative to obtain said knowhow, and to have a clear idea about how they can survive a crisis such as the coronavirus pandemic. Therefore, it is highly important to place the enterprise in a context where the coronavirus pandemic becomes a problem they can solve using their resources at hand.

The first and foremost aim of the study was to help the SMEs in the food sector to create a business and marketing strategy perspective, which can help them deal with the consequences of the COVID-19 pandemic in the future. To fulfill this aim, it was also necessary to map the accommodation processes of the food SMEs to the consequences of the restrictive COVID-19 measures, so this study also gives an insight into the changes in the marketing and innovation processes.

Relating to the abovementioned aim, the main research question was: did the family SMEs' innovation and marketing policy shift due to the coronavirus pandemic? If it did shift, how did it shift, specifically? Was the shift in policy successful? Authors considered these points, and conducted research on the Hungarian economy, trying to validate the perspectives for Hungary and its family SMEs, the food sector, and the SME sector.

In order to answer the research questions, a literature review was first performed. In this frame, we investigated the most relevant part of the literature, namely, the economic situation of the family SMEs, the marketing, and finally the innovation processes 
characterizing them. On the basis of the literature analysis, authors realized that many publications are occupied with the economic effect of the COVID-19 pandemic, but there is a lack of publications dealing with the impact of the pandemic on SMEs' innovation and marketing strategy in Hungary. In Section 3, the research material is presented; the value of the analysis lies in the time difference and not in the representativeness. In order to validate the supply side's claims on the conclusions of the coronavirus pandemic from the demand side, a conjoint analysis was performed which yielded interesting and important practical results.

\section{Overview of Literature}

\subsection{Family SMEs in the Coronavirus Pandemic}

The coronavirus pandemic has affected small and medium enterprises heavily, especially in regions where the enterprise sector is a significant pillar of the economy. Due to the quarantine measures that most countries were forced to take, potential consumers stayed at home. This resulted in revenue otherwise flowing towards small and medium enterprises becoming lost to the sector, whereas both the production volumes and the demand side of the economy heavily fluctuated due to it [11]. Polish research by Grondys et al. suggests that the main risks the SME sector had to deal with due to the coronavirus pandemic were the effects of competition gaining an increased weight due to the demand side's fluctuation as mentioned, and the general lack of revenue due to decreasing business [12]. Such significant sources of risk were identified in several other fields as well: apart from the economic crisis, a significant social crisis also began. Several worldwide examples showed that these crises related to the rapid changes in environment due to the coronavirus pandemic negatively impacted the SME sector as well [13]. It was also shown that not only economic and human issues, but management issues were either discovered or strengthened during the coronavirus pandemic - such examples are digitization [14], integration into local supply chains and cross-enterprise relations [15], and sustainability, one notable example of which is the adoption of green information systems and related elements [16]. These management issues also have an indirect effect on the survivability of SMEs during the coronavirus pandemic. The insufficiency, which was masked by the strong points of business as usual (BAU), was magnified, thereby resulting in a noticeable vulnerability for SMEs. This caused fields that would not necessarily have caused enterprises issues earlier to become more of a source of everyday issues. Cai and Luo therefore propose that improvement in such fields, especially digitization, could also improve SME performance and survivability in the SME sector-they portrayed such an effect on SMEs related to manufacturers [17]. Doyle and Cosgrove also refer to digitization, and state that it has a strong positive impact not only on properly imparting sustainability practice in the enterprise environment of SMEs, but also serving as a strong counterbalance against the uncertainty mentioned earlier [18]. Further reasoning for suppression of uncertainty lies in increasing general stability, improving the overall precision of forecasts and increasing adaptability in the midst of a volatile crisis, and making the context of the enterprise more detailed for the design of corporate policy. The impact of the coronavirus pandemic, however, caused the enterprises to have a significantly smaller area of opportunity in terms of, for example, digitization, which, in turn, caused the enterprises in question to have reduced dimensions of opportunities when employing it as well [19]. This caused insufficiencies for implementing it to counter other issues related to it as well.

Overall, the high vulnerability and the low adaptability of SMEs were both proven by the fact that the coronavirus pandemic caused this segment a large number of problems. Especially for family SMEs, which are generally trending towards the small and microenterprise size, the economic and management shock was palpable. For small enterprises in general, effectiveness and sustainability are crucial, requiring a wide arrange of considerations [20]. For logistical coherence especially, SMEs had to have an increasing consistency in effectiveness, most notably shown by the supply chain issues in the food sector. 


\subsection{The Food Sector in the Coronavirus Pandemic}

There were a multitude of sectors that were impacted due to the coronavirus pandemic, but one of the most notable examples was the foodstuffs sector. According to Aigbedo, the agriculture and foodstuffs sector suffered a harsher unemployment rate than during the 2008 Economic Depression, which was, to date, an unrivalled economic depression in the new millennium [21]. The main reason for this is the change in customer behavior, attestable to the coronavirus pandemic and its related quarantine measures. People in general started to avoid the food service industry due to the high chance of contracting the infection, and instead moved towards the food retail industry, as it necessitates fewer occasions where they need to share the same space with potentially infected people. Therefore, supply chains in the industry also had to change their patterns to adapt to the new situation, with a multitude of actions. Such actions include changing package sizes, offering discounts for mass-bought ingredients and foodstuffs, or other similar methods [22]. The general security in the sector is imperative due to the external effects as well. If there is a pandemic situation causing a quarter of the workforce employed in the agriculture and food sector to be unavailable, a global famine could immediately begin [23]. Though such an explosive situation did not happen, there have been issues related to it. This was apparent in the practice of over-purchasing during the early days of the quarantine, caused by people not trusting the supply to hold out, and searching for new procurement sources to alleviate heightened demand [24]. Therefore, preserving the strength of the supply chains turned out to be a very important undertaking in order to alleviate the impact of the coronavirus pandemic. Research indicates that the issues were very specific to the region of the supply chain-for example, analysis into the meat market suggested that the target countries of China, Russia, and the United States all had very different issues and implementable solutions. They established central economic support systems for railway transport, cold storage support, and distribution acceleration, respectively, showing that for various supply chains in the agriculture and food sector, the coronavirus pandemic caused tailored problems [25]. This view is further supported by the most notable issues highlighted by research in other countries - in the case of India, Memon et al. suggest that health and safety protocols should be introduced on the level of the individual, beyond official institutes regulating related risks through already established protocols [26]. Whelan et al. noted the impact caused by the government's communication and media information contributing to "empty shelves", while general lack of usual products and other various factors contributed to the increase in community fears and discomfort [27]. However, apart from specific issues, there were several key issues identified in relation to SMEs in the agriculture and food sector, and their issues were related to the coronavirus pandemic from the perspective of supply chains. These include, most notably, internal communication and adaptation issues, a general lack of alternative partners in the procurement of ingredients and lack of distributors, and quality-management-related issues, partly attributable to the issues in procuring materials [28].

The agriculture and food sector are therefore impacted from several points, most of which relate to the changes in the supply chain due to the coronavirus pandemic. Furthermore, while not related to the current research, it is important to note the strong connection between the agriculture and food sector's hospitality industry and the tourism industry. Due to the quarantine measures, and the nature of the crisis in question, the coronavirus pandemic, it suffered an even heavier blow, causing a backlash on especially the small and medium enterprises often considered sources of local specialties through their strong locality. This further contributed to the crisis, having heavy impact on the sectors in question.

\subsection{SME Marketing Practice during the Coronavirus Pandemic}

One of the best methods to alleviate the effects of the crisis is changing the enterprise's marketing perspective. SMEs are not too involved in marketing as a field of expertise specifically. In Hungary, several studies showed that most SMEs do not even conduct specific 
marketing, which, prior to the coronavirus pandemic, did not result in harsh backlash on the revenue of the enterprises in question. This, however, also changed during the coronavirus pandemic, most notably due to the changes in consumer preferences, following the changes in their everyday lives. Following these changes in perspective and adapting to them was imperative in surviving the coronavirus pandemic-enterprises with better adaptability were proven more successful in surviving the impact of the coronavirus pandemic [29]. Czainska et al. suggest that coronavirus, being a global crisis, requires a strongly extensive approach as well. This supports the previous example: in their study, they recommended market differentiation processes and extending marketing campaigns, in addition to classic marketing tools such as discounts, special offers, and price management, as well as market research in order to decrease the impact of the coronavirus pandemic; furthermore, they generally recommended an increase of the budget spent for marketing purposes [30]. An example of the opposite can be found in the study of Priyono et al., who state that for SMEs, the digitization state of enterprises has a direct effect on them being able to take opportunities for further digital innovation. The less developed digitally an enterprise is, the more risks in advancing further functions towards digitization, supported by their example of digitizing the sales function, and the suitability for online marketing. They find digitization important because of the extra revenue generated, which they consider the divider between continued operations and business failure [31]. Juergensen et al also consider the effects of changes in marketing - in their study, they note that a renewal of policy is a strong asset for SMEs, and marketing innovation is a possible tool in policy shift [32]. Akpan et al. also support this claim, stating that the coronavirus pandemic caused a "new normal" to emerge, where adaptation of advanced solutions will help preserve competitiveness. The example that they give for such an advanced solution in the field of marketing is the better product design and marketing sustained by analyzing smart product information sourced from Industry 4.0, post-sale services, and online social network data [33]. Specifically in the field of the food sector, we could see a tendency to refuse marketing-related innovation prior to the coronavirus pandemic. Butu et al. concluded from research into Romania's local producers that they do not have sufficient incentive in marketing to diversify into online presence going beyond Facebook, as they have deemed that this is enough for their organizational goals [34]. These producers, however, later had to "innovate their marketing strategies", according to Butu et al., which means they were similarly impacted by the effects of the coronavirus pandemic, and found similar solutions. Szalavetz further expands on this issue, stating that such online marketing possibilities were mostly beyond small-scale producers, as their technological knowhow is generally low, thereby blocking them from adequate innovation in the field, adding further stress to the food sector's SMEs [35]. Adam and Alarifi also suggest that during crises like the coronavirus pandemic, innovation of marketing and communication can give a competitive edge to SMEs, based on their research in Saudi Arabia [36]. Islam et al. came to the same conclusion in Bangladesh, citing that in spite of its agricultural development in recent years, the coronavirus pandemic caused not only a supply chain and marketing crisis, but even a production crisis in local agriculture [37]. Several other examples from other countries, with similar results from Indonesia [38], through Iran [39], to Spain [40], suggest that the conclusion regarding the marketing innovation process giving an edge to competitiveness during the coronavirus pandemic is globally applicable.

\subsection{SME Innovation Practice during the Coronavirus Pandemic}

Marketing innovation is not the only suggested form of innovation; however, the innovation of other fields also has a significant effect on the competitiveness of SMEs amidst the hardships of the coronavirus pandemic [29]. As an example, new product innovation can have a significant difference according to Iqbal et al., who analyzed scientific results of a large number of related peer-reviewed research studies [41]. Another segment of innovation, green initiatives, is also one such innovational field. Those investing are offered opportunities for increasing competitiveness and revenue, due to their dual nature 
in aiming to complete environmental and economic goals at the same time [42]. Their research is further supported by Rochedo et al., who went even further and questioned if green initiatives are even enough beyond the coronavirus pandemic; however, they explicitly stated the advantageous nature of such innovation [7]. Fodor et al. expand on the idea, and determine soft and hard skills related to green innovation in the midst of the coronavirus pandemic, in order to strengthen competency-based support for green initiatives in the labor market through higher education [43]. In conclusion, the wider the array of scientific research into innovation and its uses in boosting all manner of indicators related to economic and social development, the more it suggests that the fields of application are increasing. Gregurec et al. stress the general importance of innovation during the coronavirus pandemic in sustainable business models as well-they consider innovation to be a target process that has significant influence in the sustainability of an SME's business model, and support innovation in the strengthening of business models according to their research findings [44]. Peláez et al. go a step further, and state that the coronavirus pandemic - albeit having significant social impact, and as a global health crisisbecame a driving force behind innovation and digitization, even while causing indirect risks to health through them, characterized by the occupational risks of the quarantine period [45]. Pu et al. consider innovation to be a driving force in SME growth supported by sustainability initiatives, and even suggest government support as a catalyst to increasing the efficiency of the innovation process to boost economy and SME growth [46].

To summarize, SME innovation is considered a strong opposing force to the economic and organizational effects of the coronavirus pandemic.

\section{Materials and Methods}

This article consists of three separate research materials.

The first research material's data were collected during August 2019, where semistructured deep interviews were conducted with four family small and medium enterprises of the foodstuffs industry. This background research was then used to complete a questionnaire, which was used to collect data from 46 family SMEs referred by the participants of the interviews from the same economic area of Northeastern Hungary-all enterprises' data were supplied by either the executive in charge of the enterprise, or a spokesperson with access to relevant, necessary data. The sample selection was arbitrary. In total, 24 of the 46 family SMEs are restaurants, 9 are eateries, 8 are subsistence homesteads, and 5 are otherwise related to the local foodstuffs production or wholesale chains. These research materials were then used as a basis for the second research material.

The second research was necessary because of the pandemic situation, in order to reveal the changes. This second research was conducted with the same circle of family SMEs during early-to-mid 2021, in which interview participants commented shortly on their operations during the coronavirus pandemic. The participants of the questionnaire from the first research - if they were still operating - were asked to provide data from the interval in question. In total, 11 foodstuffs small and medium enterprise SMEs of the original 46 went out of business during the coronavirus pandemic and 35 SMEs remained. Table 1 below shows the differences between the 2019-2020 and 2021 samples.

Table 1. Differences between 2019-2020 and 2021 samples. Source: self-made.

\begin{tabular}{ccc}
\hline Sample & 2019-2020 & $\mathbf{2 0 2 1}$ \\
\hline Interview participants & 4 & 4 \\
Questionnaire participants & 46 & 35 \\
Restaurants in the sample & 24 & 17 \\
Eateries in the sample & 9 & 7 \\
Subsistence homesteads in the sample & 8 & 8 \\
Other members of the foodstuffs & 5 & 4 \\
supply chain in the sample & & \\
\hline
\end{tabular}


Most of the participants that went out of business in the sample were restaurants, which was the consequence of the restrictive measures affecting mostly the tourism and catering industries. Apart from the two eateries, one enterprise that conducts the procurement of ingredients for community catering went out of business, likely due to the decline of demand during the quarantine period in local governance.

The third research data were collected during September 2021, which were used for a conjoint analysis in order to validate the supply side's claims on the conclusions of the coronavirus pandemic from the demand side. Conjoint analysis is a widely used method in behavioral research [47]. Choice-based conjoint analysis (CBA) is a multivariate analysis used to evaluate respondents' decisions about multi-attribute choices to estimate individual utility function [48]. Individuals make decisions and tradeoffs between competing sets of attributes to select their most preferred option [49]. Conjoint analysis can create a realistic decision model by creating an environment similar to the process that real consumers choose from in the market [50]. CBA can effectively analyze choices in a sophisticated decision-making situation [51]. According to this, the authors decided to employ the full profile conjoint analysis method, which presumably offered a closer estimation of the preferences of consumers regarding innovation in general in the foodstuffs industry.

The participants in the conjoint analysis were clients referred by the enterprises, on an invitation basis. All participants were asked to participate in the research online and/or on the phone. Data collection was conducted during September 2021. The research ended with 152 participants supplying data.

The conjoint analysis focused on the purchase preferences of the participants related to opportunities for online interaction with the enterprise, the nature of the enterprise's products and services, and the nature of the enterprise's organizational outline and processes used.

The authors chose the full profile methodology of conjoint analysis; therefore, the participants were offered purchase choices, which they had to evaluate based on how desirable the choice was to them, on a 1-5 standard scale. Participants were asked to keep two things in mind while answering: to refrain from evaluating a purchase choice based on external factors not provided in the choice option itself, and to keep the coronavirus pandemic and its effects perceived by them in mind while rating.

The goals of the conjoint analysis were to obtain conclusions about the changes in the demand side's trends related to the coronavirus pandemic. The conjoint analysis was conducted with 152 participants, nominated by the still operating SMEs from their clients. The participants were asked to participate online, and the results were analyzed using the IBM SPSS Statistics 27 program pack. The conjoint analysis is not part of the SPSS program pack, however. Therefore, authors applied the analysis through the Syntax SPSS option.

All data obtained and processed were collected anonymously, and usage of data was in accordance with agreed upon guidelines.

\section{Results}

Results of the research analyses below will be presented by their research date. In this way, 2021 research results will refer back to the 2019-2020 research where applicable.

On the basis of the 2019-2020 research, the habits related to choice of marketing platform can be determined. The authors assumed the importance of the question-from the perspective of innovation management-is in modernizing. However, based on the answers given by the interview participants, it was not possible to determine if this assumption is correct. In the enterprise inherited for several generations, earlier executive generations already had an established methodology for marketing, and the current generation did not show any will to diverge from the earlier method. As for the first-generation enterprises, modern solutions were already present when the enterprises were established. The remaining enterprise had no intention of conducting specific marketing processes, as they are specialized for local clientele through connections. 
The questionnaire showed a general preference for modern marketing platforms, notably mobile applications and social media. In total, 21 of the enterprises $(46 \%)$ stated that they completely prefer online marketing platforms and methods, to the point that they do not even need offline methods of marketing. Another 12 enterprises $(26 \%)$ stated that they have both online and offline presence and they use both traditional and modern marketing platforms and methods. The two groups together show that more than twothirds of the enterprises have some form of modern marketing tool or platform presence. Most of the remaining enterprises noted that they have plans to appear online and use modern marketing methods-9 enterprises $(20 \%)$ said that they have already made steps towards establishing a presence in the online space, or will soon do so. Merely 4 enterprises $(9 \%)$ noted that they have no plans to establish social media presence or modernize their marketing toolset. Figure 1 below shows a summary of participants' answers.

\section{Is your SME planning for online marketing}

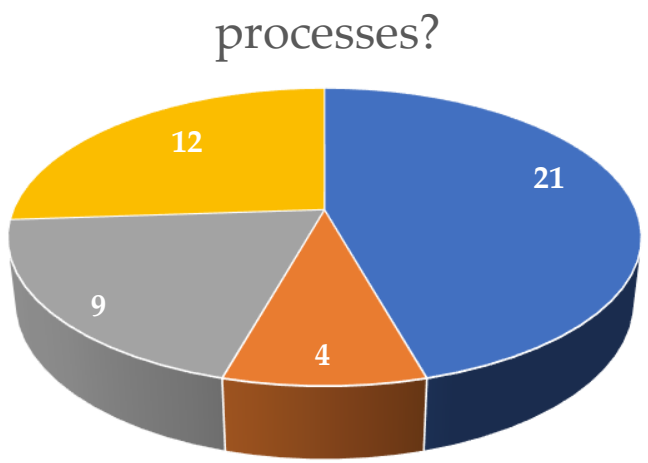

$$
\begin{aligned}
& \text { - Prefers online completely } \quad \text { Not planning on going online } \\
& \text { - Planning to go online, but not yet }=\text { Has both traditional and online }
\end{aligned}
$$

Figure 1. Attitudes towards online marketing processes in the 2019-2020 questionnaire; $n=46$, source: self-made.

The scope of planned innovation among the enterprises in the participant sample was also analyzed.

Interviews yielded results which can be said to be inversely proportional to the number of family generations at the helm of the enterprise: the first-generation enterprises not only offered examples of products and services that could be improved, they also mentioned organization specifics they wish to change, and process innovation initiatives. These generally came from issues during enterprise growth, and could attest to the malleable structure of a starting or young enterprise. The second-generation enterprise would not have started to innovate organizational structure or theory applied, most likely due to the active role of the first generation managing such issues during the early days of the enterprise. The enterprise handed down through multiple generations wished to initiate product innovation specifically, using the innovation scheme they inherited along with the enterprise.

The survey showed that the overall majority brought up examples of product innovation (this was the dominant opinion among the enterprises dealing with craft foodstuffs), but more than half of those aiming to conduct product innovation also showed incentive to conduct process innovation as well (which was the dominant opinion among restaurants). Organization innovation was not quite as popular, whereas service innovation mainly came from the nature of the enterprise (the incentive to innovate enterprise processes existed almost exclusively among restaurants and eateries, where services are a vital component to 
the enterprise process scheme). No enterprises noted that they do not intend to innovate. Figure 2 shows the innovation incentives of the enterprises.

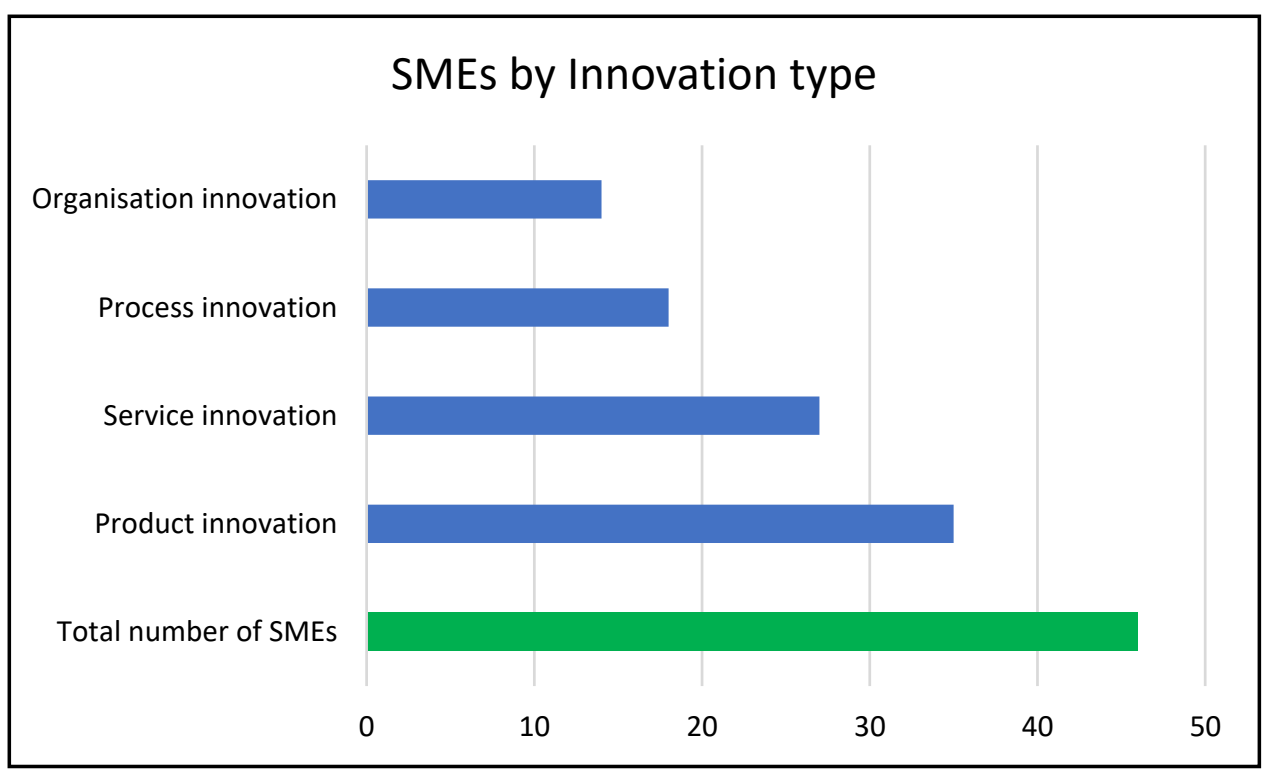

Figure 2. Planned types of innovation in the 2019-2020 questionnaire; $n=46$, source: self-made.

The 2021 research results consist of two parts: first, the enterprises that were still present in spite of the coronavirus pandemic were asked to comment on the 2019-2020 research results and contribute additional data to offer insight into their operations during the coronavirus pandemic.

The 2021 research aimed to understand the changes in marketing platform usage and its effect on organizational performance. In order to facilitate a better understanding of this, enterprises were also asked to contribute financial data in the form of expenditures on marketing processes and changes in income. Data were given in quarter year increments, and organized into percentages based on data of the same quarter during 2019. Table 2 below summarizes these percentages, while Figure 3 shows the trends on a chart.

Table 2. Enterprise online marketing expenditures and enterprise income, by quarter year, in percentages. Source: self-made.

\begin{tabular}{ccccccc}
\hline \multirow{2}{*}{ Enterprise } & $\begin{array}{c}\mathbf{2 0 2 0} \mathbf{Q 1} \\
\text { (Cost/Income) }\end{array}$ & $\begin{array}{c}\mathbf{2 0 2 0} \mathbf{Q} 2 \\
\text { (Cost/Income) }\end{array}$ & $\begin{array}{c}\mathbf{2 0 2 0} \mathbf{Q 3} \\
\text { (Cost/Income) }\end{array}$ & $\begin{array}{c}\mathbf{2 0 2 0} \mathbf{Q 4} \\
\text { (Cost/Income) }\end{array}$ & $\begin{array}{c}\mathbf{2 0 2 1} \mathbf{Q 1} \\
\text { (Cost/Income) }\end{array}$ & $\begin{array}{c}\mathbf{2 0 2 0} \mathbf{Q 2} \\
\text { (Cost/Income) }\end{array}$ \\
\hline \multirow{2}{*}{ Went online } & $22.5 \%$ & $25 \%$ & $28.7 \%$ & $36 \%$ & $31 \%$ & $29 \%$ \\
\hline \multirow{2}{*}{ Already online } & $20.4 \%$ & $26 \%$ & $34 \%$ & $44.2 \%$ & $41 \%$ & $40 \%$ \\
\cline { 2 - 7 } & $21 \%$ & $19.7 \%$ & $23 \%$ & $26.1 \%$ & $26 \%$ & $22.3 \%$ \\
\hline Offline (income) & $18 \%$ & $11.2 \%$ & $13 \%$ & $7.2 \%$ & $10 \%$ & $18 \%$ \\
\hline
\end{tabular}




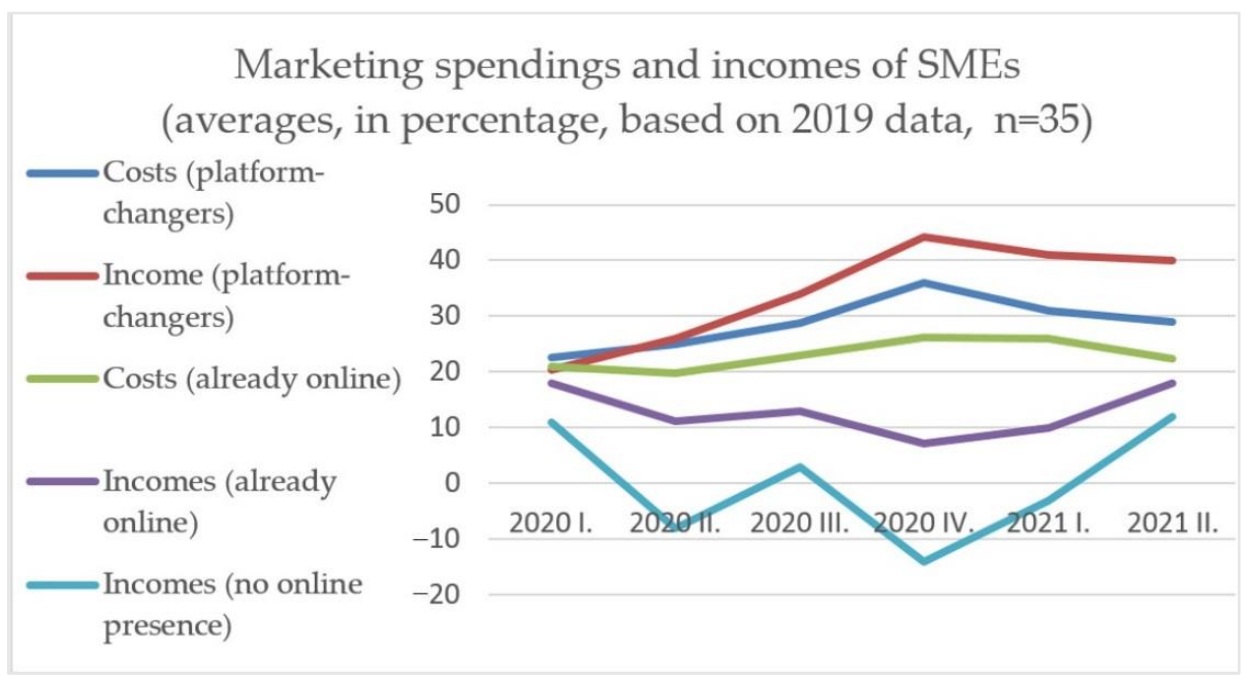

Figure 3. Trend lines based on the data of the marketing-related expenditures and incomes of enterprises in the 2021 sample; $\mathrm{n}=35$, source: self-made.

During the 2021 research, 29 enterprises' executives (83\%) stated that their enterprise had to either appear in online marketing, or had to significantly increase their presence and strengthen expenditures towards, most notably, social media. It is important to note that there is no correlation between those refusing online presence in the 2019-2020 enterprises and the enterprises that were discontinued by 2021, which suggests that there is no relation between the two groups. Family SMEs that established an online presence were able to increase profits even at the cost of increased expenditures, whereas those that strengthened their presence and increased marketing-related expenditures in the online space were also able to obtain benefits (note that this assumption is based on the SMEs' own calculations). Another key point to note is how those that established an online presence had more significant results, which is likely due to reaching new customers. As clearly shown by the enterprises that refused to appear online, those advertising online managed to avoid greater losses in both cases. The enterprises refusing to establish an online presence were mostly aided by local community efforts and subsidies. None of the other enterprises reported having to obtain loan funding.

Moreover, as seen during early 2021, the restarting economy (and most notably the discontinuation of quarantine regulations) offered a great opportunity for enterprises that were more exposed to the effects of the coronavirus pandemic to generate more revenue. Another cause for this economic activity is that the populace, which had to undergo quarantine for a long time, had more initiative to spend and had more disposable income as they could not spend at their usual rate due to fewer opportunities caused by a lack of offline social life events.

Mapping of the coronavirus effect on planned innovation activities was also an important aim of the research. In terms of the assumptions that could be drawn from the 2019-2020 research, the 2021 research yielded the expected results. Nearly all of the enterprises, 31 in total $(89 \%)$, noted that they began process innovation as a coping mechanism against the effects of the coronavirus pandemic on the usual business process. Most notable innovation targets for the process innovation were introducing different production methods, delivery service rationalization or establishing of delivery service, and eight enterprises (23\%) also reported establishing packet point partnerships for fresh produce (which was mostly, but not exclusively, relevant for the subsistence homesteads). Six enterprises $(17 \%)$ noted that they restructured logistics and warehousing as well. It is important to note that 17 enterprises $(49 \%)$ already had delivery services, but almost all of them reported that they changed it in some way due to the effects of the coronavirus pandemic. 


\section{Results of the Conjoint Analysis}

A conjoint analysis was conducted to obtain results from the demand side, gaining more relevant knowledge about the coronavirus pandemic's effect on the family SMEs related to foodstuffs. The importance of the demand side lies in the perception towards the changes on the supply side. Only changes that are in line with shifts in demand can be successful, especially in the long-term, which is why the authors decided to use the demand side to validate their findings on the supply side. It is also important to note that the demand side and the supply side may have different points of interest when deliberating their perspective on the same change of an enterprise. The closer the gap between the two is, the more efficient the changes made, and the better the demand side's satisfaction, the more advantageous the changes are.

Conjoint analysis was the choice of the authors in order to reduce the pressure of the coronavirus pandemic as a topic. In order to facilitate a test to both evaluate and validate the choices made by the SMEs in changing their methods for reaching their customers, the authors determined a method which will induce customers to make choices based on the changes in their perception that will remind them of the pandemic, which was preferred to one that would influence their choices because of the pandemic. This criterion is satisfied by the conjoint analysis method, and according to authors' expectations, could safely remove the excessive impact of the coronavirus pandemic on the analysis.

The conjoint analysis used the attributes of reach and innovation form, the latter of which was considered separately for product and service, and organization and process pairs. Levels by attribute were two-tiered, levels for reach were in person and online, whereas levels for the product and service and organization and process pairs were innovative and traditional. The resulting eight levels were used to create an orthogonal design of eight separate cards, which fulfils the criteria of a conjoint analysis in the SPSS Statistics program pack. Examples were provided to the participants to facilitate understanding of the various combinations of levels. Table 3 below shows the summary of the cards available for participants to evaluate.

Table 3. Summary of orthogonal designs used for conjoint analysis. Source: self-made.

\begin{tabular}{ccccc}
\hline Card & Reach & $\begin{array}{c}\text { Service/ } \\
\text { Product }\end{array}$ & $\begin{array}{c}\text { Organization/ } \\
\text { PROCESS }\end{array}$ & $\begin{array}{c}\text { Summary of the Example } \\
\text { Provided }\end{array}$ \\
\hline Card 1 & Online & Traditional & Traditional & Applying for "pick it yourself" fruit purchase \\
\hline Card 2 & Personal & Traditional & Traditional & Restaurant order from digital menu \\
\hline Card 3 & Personal & Innovative & Innovative & Pre-order of processed foodstuff \\
\hline Card 4 & Online & Innovative & Innovative & Webshop food order with delivery \\
\hline Card 5 & Online & Traditional & Innovative & Ordering food supplement through phone \\
\hline Card 6 & Personal & Traditional & Innovative & Placing order for foreign spice mixture with \\
delivery in the shop
\end{tabular}

Results showed that data of the conjoint analysis were usable to analyze preferences. Although correlation values had slight deviation from statistical significance $(p=0.069)$, most likely a result of the size of the sample being slightly small for the 8-card conjoint analysis, due to relatively good statistical correlation between observed and estimated preferences (Pearson's R $=0.573$; Kendall's tau $=0.429$ ), the conclusion of the analysis can be accepted in the context of the analysis. Standard error of partial utilities was relatively low, at 0.182 . Table 4 shows summarized data on the answers of the 152 participants. 
Table 4. Summary of participant answers; $\mathrm{n}=152,1-5$ favorability scale. Source: self-made.

\begin{tabular}{ccccc}
\hline Card & Average & Deviation & Coefficient of Variation & Conclusion Based on CeV Compared to Avg and Dev \\
\hline Card 1 & 2.99 & 1.24 & 0.41 & Low favorability, low consistency \\
\hline Card 2 & 3.30 & 1.32 & 0.40 & Low favorability, low consistency \\
\hline Card 3 & 3.61 & 0.96 & 0.27 & Average favorability, high consistency \\
\hline Card 4 & 3.97 & 1.22 & 0.31 & High favorability, low consistency \\
\hline Card 5 & 3.38 & 1.18 & 0.35 & Average favorability, low consistency \\
\hline Card 6 & 4.07 & 0.93 & 0.23 & High favorability, high consistency \\
\hline Card 7 & 4.47 & 0.80 & 0.18 & Very high favorability, high consistency \\
\hline Card 8 & 3.25 & 0.85 & 0.26 & Low favorability, high consistency \\
\hline
\end{tabular}

As seen in the table, cards 6 and 7 were the variants that had the highest popularity (placing an order for a delivery in the shop; using a net waiter application), whereas the lowest popularity was given to cards 1 and 2 (applying online for a "pick it yourself" fruit wholesale; completing order through digital menu in restaurant). The lowest consistency was also given to cards 1 and 2, however, which means that while they are overall the most unpopular among participants, the opinions on it also differed the most, whereas the highest consistency similarly showed up for cards 6 and 7, which means their position (and them being the most popular choices) was also the least contested. Results also suggest that instead of purely traditional or purely modern, participants prefer a mix of traditional and innovative elements.

Table 5 shows the partial utilities and importance values of the conjoint analysis.

Table 5. Summary of conjoint plan results. $\mathrm{n}=152$, std. error $=0.182$. Source: self-made.

\begin{tabular}{|c|c|c|c|}
\hline Attributes & Importance Values & Levels & Partial Utilities \\
\hline \multirow{2}{*}{ Accessibility } & \multirow{2}{*}{8019} & Personally accessible & -0.028 \\
\hline & & Online accessible & 0.028 \\
\hline \multirow{2}{*}{ Service and Product Innovativeness } & \multirow{2}{*}{68,868} & Traditional solutions & -0.240 \\
\hline & & Innovative solutions & 0.240 \\
\hline \multirow{2}{*}{ Organization and Process Innovativeness } & \multirow{2}{*}{23,113} & Traditional solutions & 0.081 \\
\hline & & Innovative solutions & -0.081 \\
\hline
\end{tabular}

Due to the specific sector in question, it is of no surprise that the most important factors for the participants were the products and services. Another unsurprising conclusion is that the organization and process innovation were considered less important, since the changes in how we conduct ourselves in person due to the coronavirus pandemic and the changes in the context of on-site purchases and consumption did not have as harsh of an impact on the participants since they were already used to being at home. Perhaps the only surprising result could be the low importance of accessibility. However, it is natural that this resulted in low importance, as being accessible online in light of the coronavirus pandemic is less important for the consumer than for the enterprise-whereas the consumer has a wide variety of choices they can select from when ordering online. As such, since they are used to having this option, enterprises could easily fail due to insufficient online presence, as we could see in the marketing trend lines earlier.

In conclusion, the consumers' answers show that when considering the changes brought about by the coronavirus pandemic, the conjoint analysis on the consumer demand side was compatible with the best practices of marketing and innovation employed by the enterprises on the supply side, and the conjoint analysis results can be sufficiently explained by social changes during the coronavirus pandemic. 


\section{Discussion}

The results of the 2019-2020 and the 2021 research were successful in proving that the coronavirus pandemic caused additional stress to the family SMEs so that they needed to make fundamental changes to survive. This is an important issue for Hungary's SME sector in particular, due to the employment characteristics [52] and spillover effects, primarily in the supply chain and the business environment [53]. In media, we could often see and hear how vulnerable the SMEs are to the effects of the coronavirus pandemic due to the intricacies of the SME sector and the economic instability brought about by the virus causing the business as usual (BAU) routine to fall apart. The research of the authors also proved that this process is excessively prevalent for family SMEs working in the foodstuffs sector. There are various reasons for this-the changes in the catering sector, the reliance on the supply chain, etc. The family SMEs in the foodstuffs sector being the notable example is due to the unique situation caused by the coronavirus pandemic having high correlation to issues with both the catering and the SME sectors' relevant specifics, such as the aforementioned supply chains.

Based on results obtained, we can say that for the family SMEs dealing with foodstuff ingredients or foodstuffs, the most important factor is to adopt a logistics perspective and system that can be immediately switched to in case the necessity arises. As explained by Lukács and Csiszárik, the Hungarian SME sector is susceptible to crises, which necessitates the proper capacity to adapt [54]. Furthermore, it is worth mentioning that a similar capacity for adaptation may be necessary for marketing processes as well. Authors' results show that logistics and marketing had a high impact on the survivability of family SMEs during the coronavirus pandemic. At the very least, enterprises should reach a level in terms of marketing processes where they could migrate all elements of marketing conducted outside of special circumstances such as the coronavirus pandemic onto a platform that either nullifies or at least successfully resists changes in reach and efficiency. This conclusion is further supported by the results of the conjoint analysis.

Another important result of the conjoint analysis is the differences in perception towards the impact of online reach-whereas the SMEs experienced increases in reach using social media, thereby finding it important, the conjoint analysis returned a low importance score. This is in relation to perception shaping-Obermayer et al. proved that social media is an important asset to increase the reach of Hungarian SMEs [55].

There are also two valuable novelties in the results of the research: for one, the results showed that there is necessity for the progress of business innovation beyond generic technological innovation (i.e., appearing on digital platforms, digitization) and traditional product and service innovation for the family SMEs in the Hungarian food sector. Business innovation is an undertaking that follows closely after the types of innovation that SMEs that were asked to participate in the research wished to conduct, and specific research results, especially the differences between SMEs that appeared on the digital advertisement platform and those that did not, show clearly how innovating the business model is a necessity during a pandemic. This further shows the importance of skill development, as SMEs tend to not develop specific expert skills towards marketing. In spite of this, skill development is a necessary input for family businesses in Hungary to begin with, according to Szigeti and Józsa [56], which is further stressed by the coronavirus pandemic, making the issue related to innovation more susceptible to time. These results fundamentally show how important marketing is for SMEs, even though it is considered a less important factor for a small enterprise.

The other novelty is that Hungarian consumers have a preference towards a mix of traditional and innovative elements in terms of the foodstuffs establishments they visit. Generally, a nation's attitude is categorized either into preference for traditional values or innovation, as seen in, for example, Hofstede's works regarding orientation. Hofstede's own cultural research describes Hungary as a pragmatic country, assuming affinity for to innovative solutions. However, the research results from the conjoint analysis indicate that preference towards mixed alternatives was stronger, and at the same time, deviation in 
opinions was lesser. This indicates a fairly important point to note for food sector SMEs. It is important to innovate, and just as important to conserve values, but the SME must be prepared to have a strong basis to decide which enterprise elements to innovate, and which to conserve in tradition. This finding, albeit in different form, is in line with an earlier research study conducted by Kühne et al., who reached similar findings regarding the perception of innovation on the food sector among Hungarians [57]. From this aspect, the conjoint analysis managed to bring a strong foundation in the preference of consumers, post-coronavirus pandemic. It should also be emphasized, due to its practical contribution, that the importance of the traditional elements in purchasing from the side of the Hungarian consumers should be built into the strategy of the SMEs.

Conducting innovation and focusing on marketing during a crisis such as the coronavirus pandemic is, as of yet, not a deeply analyzed topic for Hungary, due to the nature of the coronavirus pandemic and its novel effects on our economy. However, recent literature shows that the results of this article are not incorrect. Potori et al. recommend that R\&D spending and innovation and marketing expenditures in the agro-food sector should be increased during a crisis [58]. Nyikos et al. further establish this claim in their study specifically on SME survivability and the coronavirus pandemic, mentioning that SMEs that obtained financing and spent it for marketing and innovation during the coronavirus pandemic had stronger resilience and better prospects [59]. Wicaksono et al. also extended the importance of marketing for local agricultural producers towards digital media. In their research, they stressed the general importance of digital media appearance, which is a key to those purchasing agricultural products of short supply chains [60]. In conclusion, scarce research into the innovation habits of Hungarian SMEs during a crisis suggests that while the coronavirus pandemic intensified the risks, earlier crises showed innovation and marketing investment to be a good counter.

The enterprises that discontinued operations between the 2019 and the 2021 research are sad examples of how the capability to follow consumer trends is a necessity in the toolkit of SMEs, even if the consumer trend in question was caused directly by a global pandemic situation. This research should highlight that the coronavirus pandemic made rethinking and proper pacing of organizational operations, creative usage of marketing communications, and innovation more important than ever. The proper care in these fields may help reduce enterprise risks in the crisis period, and preserve enterprise competitiveness - or, in certain cases, even increase it - while, at the same time, reducing or fixing operational issues.

The authors' opinion is that continuing, and if necessary, extending this research to more areas is important not only for a future, potential pandemic situation that could be handled more reliably through it, but for increasing competitiveness of the SME sector in general as well.

\section{Limitations}

Although useful conclusions can be drawn from the results, they are subject to limitations. While the study mainly deals with the family SMEs selling either foodstuff materials or finished foodstuffs, meaning we can have a very specific and detailed outlook on the segment in the region and the general hardships they went through during the coronavirus pandemic, the applicability of results obtained in this research have limitations from several perspectives. First, it is important to note that small and medium enterprises in this specific sector are more significantly dependent on the supply chain when compared to enterprises offering different products or services of a different nature, which makes research results related to these supply chains possibly less significant in other sectors.

The main issue in relation to applicability is the low number of sample cases: family SMEs that the authors corresponded with in the first phase of the research were not that numerous to begin with, and this low case number could not be increased even in the second research during 2021, due to the nature of the research itself. As research representativeness is somewhat less important in this case, and the research correlations on the sample are 
well-defined, the research results have high precision for the sector segment in question. Still, it is hard to say in any capacity that they are representative results.

A similar problem comes up with the second data collection and research instance. This served as the basis for the conjoint analysis. As the family SMEs were asked to refer the authors to their repeat customers for the data collection necessary to conduct the conjoint analysis, we can safely assume that the positive attitude towards the establishment that referred the participants also made them more calculated in giving their answers, based on the nature of the establishments that referred them.

A positive factor close to this problem, however, also an inhibitor in the research itself, is the nature of results obtained from the research. According to economic and social processes we already know or have detailed information on, we can state that while some of the results are quasi-obvious, statistically validating their conclusions offered could serve as a basis for SME strategizing during future economic and social crises. In terms of innovation, it is important to find methods for increasing adaptation capacity, as economy during a crisis is a highly volatile context. This volatile context can easily cause a myriad of small changes, each of which may become a key factor in not only preserving competitiveness, but even for survival itself for SMEs. However, universally grouping SMEs which are able to utilize these results is impossible.

The next important factor necessary to mention about the research is that the range of conducted business activities limits the applicability of research results. We experienced that there may be a wide array of issues related to foodstuffs during a quarantine period, as even the largest of grocery chains could not weather the coronavirus pandemic fully. Naturally, we know sectors and product lines which were impacted even more (prime examples being healthcare services, medical tools and implements, and disinfectant chemicals, to name a few that came up during the coronavirus quarantine) in the SME sector. These issues mostly came up for retailers, small local stores, and generally SMEs; however, in certain cases, even production enterprises that manufacture worldwide had issues with these products and services. This suggests that the research results obtained by the authors are not usable or are only partially usable to model the issues of other members of the SME sector.

Author Contributions: Conceptualization, N.B., Z.F. and K.N.P.; Investigation, N.B. and K.N.P.; Methodology, Z.F.; Resources, N.B.; Software, Z.F.; Supervision, N.B. and K.N.P.; Visualization, N.B. and Z.F.; Writing—original draft, N.B.; Writing—review \& editing, K.N.P. All authors have read and agreed to the published version of the manuscript.

Funding: This research received no external funding.

Institutional Review Board Statement: Not applicable.

Informed Consent Statement: Not applicable.

Data Availability Statement: Not applicable.

Acknowledgments: Special acknowledgement to Éva Zsuzsanna Járási for her assistance with the statistical data evaluation process.

Conflicts of Interest: The authors declare no conflict of interest.

\section{References}

1. Caggiano, G.; Castelnuovo, E.; Kima, R. The global effects of COVID-19-induced uncertainty. Econ. Lett. 2020, 194, 109392. [CrossRef] [PubMed]

2. Baker, S.; Bloom, N.; Davis, S.; Kost, K.; Sammon, M.; Viratyosin, T. The unprecedented Stock Market reaction to COVID-19. Rev. Asset Pricing Stud. 2020, 10, 742-758. [CrossRef]

3. Talani, L.S.; De Bellis, F. The Response to COVID-19 by the Italian Populist Government: Is It Populism or Neo-Liberalism That Has Made the Response to the Pandemic Inadequate? Soc. Sci. 2021, 10, 336. [CrossRef]

4. Ghanemi, A.; Yoshioka, M.; St-Amand, J. Coronavirus Disease 2019 (COVID-19) Crisis Measures: Health Protective Properties? Medicines 2021, 8, 49. [CrossRef]

5. Turon, K.; Kubik, A. Business Innovations in the New Mobility Market during the COVID-19 with the Possibility of Open Business Model Innovation. J. Open Innov. Technol. Mark. Complex. 2021, 7, 195. [CrossRef] 
6. Malec, M.; Kinelski, G.; Czarnecka, M. The Impact of COVID-19 on Electricity Demand Profiles: A Case Study of Selected Business Clients in Poland. Energies 2021, 14, 5332. [CrossRef]

7. Rochedo, P.R.R.; Fragkos, P.; Garaffa, R.; Couto, L.C.; Baptista, L.B.; Cunha, B.S.L.; Schaeffer, R.; Szklo, A. Is Green Recovery Enough? Analysing the Impacts of Post-COVID-19 Economic Packages. Energies 2021, 14, 5567. [CrossRef]

8. Tavares, F.; Santos, E.; Diogo, A.; Ratten, V. Teleworking in Portuguese communities during the COVID-19 pandemic. J. Enterprising Communities People Places Glob. Econ. 2021, 15, 334-349. [CrossRef]

9. Azevedo, A.; Almeida, A.H. Grasp the Challenge of Digital Transition in SMEs-A Training Course Geared towards DecisionMakers. Educ. Sci. 2021, 11, 151. [CrossRef]

10. Marjanski, A.; Sułkowski, Ł. Consolidation strategies of small family firms in Poland during Covid-19 crisis. Entrep. Bus. Econ. Rev. 2021, 9, 167-182. [CrossRef]

11. Kraus, S.; Clauss, T.; Breier, M.; Gast, J.; Zardini, A.; Tiberius, V. The economics of COVID-19: Initial empirical evidence on how family firms in five European countries cope with the corona crisis. Int. J. Entrep. Behav. 2020, 26, 1067-1092. [CrossRef]

12. Grondys, K.; Slusarczyk, O.; Hussain, H.; Androniceanu, A. Risk assessment of the SME sector operations during the COVID-19 pandemic. Int. J. Environ. Res. Public Health 2021, 18, 4183. [CrossRef]

13. Mansour, A.; Al Shibi, A.; Khalifeh, A.; Mansour, L. Health-care workers' knowledge and management skills of psychosocial and mental health needs and priorities of individuals with COVID-19. Ment. Health Soc. Incl. 2020, 24, 135-144. [CrossRef]

14. Akpan, I.; Soopramanien, D.; Kwak, D. Cutting-edge technologies for small business and innovation in the era of COVID-19 global health pandemic. J. Small Bus. Entrep. 2021, 33, 607-617. [CrossRef]

15. Ali, Z.; Gongbing, B.; Mehreen, A. Does supply chain finance improve SMEs performance? The moderating role of trade digitization. Bus. Process Manag. J. 2018, 26, 150-167. [CrossRef]

16. Baggia, A.; Maletič, M.; Žnidaršič, A.; Brezavšček, A. Drivers and Outcomes of Green IS Adoption in Small and Medium-Sized Enterprises. Sustainability 2019, 11, 1575. [CrossRef]

17. Cai, M.; Luo, J. Influence of COVID-19 on Manufacturing Industry and Corresponding Countermeasures from Supply Chain Perspective. J. Shanghai Jiaotong Univ. 2020, 25, 409-416. [CrossRef]

18. Doyle, F.; Cosgrove, J. Steps towards digitalization of manufacturing in an SME environment. Procedia Manuf. 2019, 38, 540-547. [CrossRef]

19. Katz-Gerro, T.; Lopez Sintas, J. Mapping circular economy activities in the European Union: Patterns of implementation and their correlates in small and medium-sized enterprises. Bus. Strategy Environ. 2019, 28, 485-496. [CrossRef]

20. Ciemleja, G.; Lace, N. The model of Sustainable Performance of Small and Medium-sized Enterprises. Eng. Econ. 2011, 22, 50-509. [CrossRef]

21. Aigbedo, H. Impact of COVID-19 on the hospitality industry: A supply chain resilience perspective. Int. J. Hosp. Manag. 2021, 98, 103012. [CrossRef]

22. Hobbs, J. Food supply chain resilience and the COVID-19 pandemic: What have we learned? Can. J. Agric. Econ. 2021, 69, 189-196. [CrossRef]

23. Huff, G.; Beyeler, E.; Kelley, S.; McNitt, A. How resilient is the United States' food system to pandemics? J. Env. Stud. Sci. 2015, 5 , 337-347. [CrossRef]

24. Loxton, M.; Truskett, R.; Scarf, B.; Sindone, L.; Baldry, G.; Zhao, Y. Consumer Behaviour during Crises: Preliminary Research on How Coronavirus Has Manifested Consumer Panic Buying, Herd Mentality, Changing Discretionary Spending and the Role of the Media in Influencing Behaviour. J. Risk Financ. Manag. 2020, 13, 166. [CrossRef]

25. Zielińska-Chmielewska, A.; Mruk-Tomczak, D.; Wielicka-Regulska, A. Qualitative Research on Solving Difficulties in Maintaining Continuity of Food Supply Chain on the Meat Market during the COVID-19 Pandemic. Energies 2021, 14, 5634. [CrossRef]

26. Memon, S.U.R.; Pawase, V.R.; Pavase, T.R.; Soomro, M.A. Investigation of COVID-19 Impact on the Food and Beverages Industry: China and India Perspective. Foods 2021, 10, 1069. [CrossRef] [PubMed]

27. Whelan, J.; Brown, A.D.; Coller, L.; Strugnell, C.; Allender, S.; Alston, L.; Hayward, J.; Brimblecombe, J.; Bell, C. The Impact of COVID-19 on Rural Food Supply and Demand in Australia: Utilising Group Model Building to Identify Retailer and Customer Perspectives. Nutrients 2021, 13, 417. [CrossRef] [PubMed]

28. Ferreira, C.; Cardoso, C.; Travassos, M.; Paiva, M.; Pestana, M.; Lopes, J.M.; Oliveira, M. Disorders, Vulnerabilities and Resilience in the Supply Chain in Pandemic Times. Logistics 2021, 5, 48. [CrossRef]

29. Rashid, S.; Ratten, V. Entrepreneurial ecosystems during COVID-19: The survival of small businesses using dynamic capabilities. World J. Entrep. Manag. Sustain. Dev. 2021, 17, 457-476. [CrossRef]

30. Czainska, K.; Sus, A.; Thalassinos, E.I. Sustainable Survival: Resource Management Strategy in Micro and Small Enterprises in the Rubber Products Market in Poland during the COVID-19 Pandemic. Resources 2021, 10, 85. [CrossRef]

31. Priyono, A.; Moin, A.; Putri, V.N.A.O. Identifying Digital Transformation Paths in the Business Model of SMEs during the COVID-19 Pandemic. J. Open Innov. Technol. Mark. Complex. 2020, 6, 104. [CrossRef]

32. Juergensen, J.; Guimón, J.; Narula, R. European SMEs amidst the COVID-19 crisis: Assessing impact and policy responses. J. Ind. Bus. Econ. 2020, 47, 499-510. [CrossRef]

33. Akpan, I.; Abasifreke, E.; Udoh, P.; Adebisi, B. Small business awareness and adoption of state-of-the-art technologies in emerging and developing markets, and lessons from the COVID-19 pandemic. J. Small Bus. Entrep. 2020, 10, 1-18. [CrossRef] 
34. Butu, A.; Brumă, I.S.; Tanasă, L.; Rodino, S.; Dinu Vasiliu, C.; Doboș, S.; Butu, M. The Impact of COVID-19 Crisis upon the Consumer Buying Behavior of Fresh Vegetables Directly from Local Producers. Case Study: The Quarantined Area of Suceava County, Romania. Int. J. Environ. Res. Public Health 2020, 17, 5485. [CrossRef]

35. Szalavetz, A. Digital transformation-Enabling factory economy actors' entrepreneurial integration in global value chains? Post-Communist Econ. 2020, 32, 771-792. [CrossRef]

36. Adam, N.A.; Alarifi, G. Innovation practices for survival of small and medium enterprises (SMEs) in the COVID-19 times: The role of external support. J. Innov. Entrep. 2021, 10, 15. [CrossRef] [PubMed]

37. Islam, T.; Talukder, A.K.; Siddiqui, N.; Islam, T. Tackling the COVID-19 pandemic: The Bangladesh perspective. J. Public Health Res. 2020, 9, 1794. [CrossRef]

38. Patma, T.; Wardana, L.; Wibowo, A.; Narmaditya, B.; Akbarina, F. The impact of social media marketing for Indonesian SMEs sustainability: Lesson from Covid-19 pandemic. Cogent Bus. Manag. 2020, 8, 1953679. [CrossRef]

39. Salamzadeh, A.; Dana, L.P. The coronavirus (COVID-19) pandemic: Challenges among Iranian startups. J. Small Bus. Entrep. 2021, 33, 489-512. [CrossRef]

40. Jiménez-Marín, G.; Elías Zambrano, R.; Galiano-Coronil, A.; Ravina-Ripoll, R. Business and Energy Efficiency in the Age of Industry 4.0: The Hulten, Broweus and Van Dijk Sensory Marketing Model Applied to Spanish Textile Stores during the COVID-19 Crisis. Energies 2021, 14, 1966. [CrossRef]

41. Iqbal, M.; Suzianti, A. New Product Development Process Design for Small and Medium Enterprises: A Systematic Literature Review from the Perspective of Open Innovation. J. Open Innov. Technol. Mark. Complex. 2021, 7, 153. [CrossRef]

42. Schiederig, T.; Tietze, F.; Herstatt, C. Green Innovation in Technology and Innovation Management-An Exploratory Literature Review. RD Manag. 2012, 42, 180-192. [CrossRef]

43. Fodor, S.; Szabó, I.; Ternai, K. Competence-Oriented, Data-Driven Approach for Sustainable Development in University-Level Education. Sustainability 2021, 13, 9977. [CrossRef]

44. Gregurec, I.; Tomičić Furjan, M.; Tomičić-Pupek, K. The Impact of COVID-19 on Sustainable Business Models in SMEs. Sustainability 2021, 13, 1098. [CrossRef]

45. López Peláez, A.; Erro-Garcés, A.; Pinilla García, F.J.; Kiriakou, D. Working in the 21st Century. The Coronavirus Crisis: A Driver of Digitalisation, Teleworking, and Innovation, with Unintended Social Consequences. Information 2021, 12, 377. [CrossRef]

46. Pu, G.; Qamruzzaman, M.; Mehta, A.M.; Naqvi, F.N.; Karim, S. Innovative Finance, Technological Adaptation and SMEs Sustainability: The Mediating Role of Government Support during COVID-19 Pandemic. Sustainability 2021, 13, 9218. [CrossRef]

47. Plasek, B.; Lakner, Z.; Temesi, Á. I Believe It Is Healthy-Impact of Extrinsic Product Attributes in Demonstrating Healthiness of Functional Food Products. Nutrients 2021, 13, 3518. [CrossRef]

48. Green, P.E.; Krieger, A.M.; Wind, Y. Thirty years of conjoint analysis: Reflections and prospects. Interfaces 2001, 31, S56-S73. [CrossRef]

49. Lancaster, K.J. A new approach to consumer theory. In Mathematical Models in Marketing: A Collection of Abstracts; Springer: Berlin/Heidelberg, Germany, 1976; pp. 106-107.

50. Kim, J.; Kim, M.; Im, S.; Choi, D. Competitiveness of E Commerce Firms through ESG Logistics. Sustainability 2021, $13,11548$. [CrossRef]

51. Raghavarao, D.; Wiley, J.; Chitturi, P. Choice-Based Conjoint Analysis; Chapman and Hall/CRC: New York, NY, USA, 2010. [CrossRef]

52. Karácsony, P. The impact of the coronavirus (COVID-19) on the employment characteristics of Hungarian SMEs. Virgil Madgearu Rev. Econ. Stud. Res. 2020, 13, 105-117. [CrossRef]

53. Karácsony, P. Effects of the Coronavirus Crisis on Hungarian Small and Medium-Sized Enterprises. In Polgári Szemle: Gazdasági És Társadalmi Folyóirat; Library of the Hungarian Academy of Sciences: Budapest, Hungary, 2020; pp. 434-444. ISSN 1786-6553.

54. Lukács, E.; Csiszárik, M. The performance of hungarian and European SME's. In Scientific Bulletin of Uzhgorod University: Series: Economics; Uzhhorod National University Publishing House: Uzhhorod, Ukraine, 2011; pp. 180-181.

55. Obermayer, N.; Kővári, E.; Leinonen, J.; Bak, G.; Valeri, M. How social media practices shape family business performance: The wine industry case study. Eur. Manag. J. 2021; in press. [CrossRef]

56. Szigeti, S.Z.; Józsa, L. Impact of the coronavirus pandemic on the marketing approach of Hungarian entrepreneurs in Slovakia. In FIKUSZ 2021 Proceedings; Kelemen-Erdos, A., Feher-Polgar, P., Popovics, A., Eds.; Obuda University, Keleti Károly Faculty of Business and Management: Budapest, Hungary, 2021; pp. 48-57. ISBN 978-963-449-274-0.

57. Kühne, B.; Vanhonacker, F.; Gellynck, X.; Verbeke, W. Innovation in traditional food products in Europe: Do sector innovation activities match consumers' acceptance? Food Qual. Prefer. 2010, 21, 629-638. [CrossRef]

58. Potori, N.; Garai, R.; Popp, J. Lessons learned from the impacts of the global financial and economic crisis ont he agro-food sector of Hungary. Econ. Rural. Dev. 2010, 6, 7-16.

59. Nyikos, G.; Soha, B.; Béres, A. Entrepreneurial Resilience and Firm Performance during the COVID-19 Crisis-Evidence from Hungary; Hungarian Central Statistical Office: Budapest, Hungary, 2021; Volume 11, pp. 29-59.

60. Wicaksono, T.; Nugroho, A.D.; Lakner, Z.; Dunay, A.; Illés, C.B. Word of Mouth, Digital Media, and Open Innovation at the Agricultural SMEs. J. Open Innov. Technol. Mark. Complex. 2021, 7, 91. [CrossRef] 